\title{
Experimental Evidence for Three Pheromone Races of the Scarab Beetle Phyllophaga anxia (LeConte)
}

\author{
Paul S. Robbins • Daniel B. Cash • Charles E. Linn, Jr • \\ Wendell L. Roelofs
}

Received: 7 December 2006 /Revised: 7 October 2007 / Accepted: 4 January 2008 /Published online: 24 January 2008

(C) Springer Science + Business Media, LLC 2008

\begin{abstract}
This study offers experimental evidence for the existence of three pheromone races of the northern genitalic form of Phyllophaga anxia: one race in which females produce and males respond mainly to L-valine methyl ester, a second producing and responding to L-isoleucine methyl ester, and a third producing and responding to an intermediate range of blends of the two compounds. At Franklinville, NY, pheromone gland contents of females were analyzed using coupled gas chromatography-electroantennogram detection. Two types of females were found, one that produced greater than $99 \%$ L-valine methyl ester and another that produced greater than 99\% Lisoleucine methyl ester. Capture-mark-release-recapture field tests with males at Franklinville established that most males were recaptured in traps baited with the same blends with which they were originally captured. The populations characterized at Franklinville, NY, have also been found at numerous locations from eastern Canada and the northeast and north central USA, sometimes in allopatry and sometimes in sympatry. At a site in Carver, MA, P. anxia males responded to blends of the methyl esters of L-valine and L-isoleucine, and Carver females produced blends similar to those to which the males responded. Populations responding to blends have been identified only from southeastern Massachusetts and Rhode Island. At a field site near Waterloo, NY, the addition of small proportions of
\end{abstract}

\footnotetext{
P. S. Robbins $(\varangle) \cdot$ C. E. Linn, Jr $\cdot$ W. L. Roelofs

Department of Entomology,

New York State Agricultural Experiment Station,

Cornell University,

Geneva, NY 14456, USA

e-mail: psr1@cornell.edu

D. B. Cash

P.O. Box 282, Angelica, NY 14709, USA
}

L-isoleucine methyl ester to lures containing L-valine methyl ester did not affect trap captures, but higher proportions of L-isoleucine methyl ester were inhibitory, decreasing trap captures.

Keywords L-Isoleucine methyl ester - L-Valine methyl ester . Sex pheromone $\cdot$ Scarabaeidae $\cdot$ Melolonthinae . Pheromone races

\section{Introduction}

In a multiyear North American study involving the capture and identification of approximately 57,000 individuals in 61 species of scarab beetles in the genus Phyllophaga, Robbins et al. (2006) documented the existence of geographic variation of male response of the northern genitalic form of Phyllophaga anxia to various blends of the two sex attractant components of this species. P. anxia is described as having two distinctive genitalic types, commonly called northern or southern (see Luginbill and Painter 1953 or Woodruff and Beck 1989 for photographs or scanning electron micrographs of the two forms). P. anxia is perhaps the most widely distributed (Luginbill and Painter 1953; Woodruff and Beck 1989) of the approximately 215 species (Evans and Smith 2007) of Phyllophaga in the USA and Canada. The larval stages of $P$. anxia are serious root-feeding pests of commercial cranberry crops in Massachusetts and Wisconsin (Franklin 1950; Dittl and Kummer 1997).

In the study of Robbins et al. (2006), traps were baited with various blends of the methyl esters of L-valine and Lisoleucine, the sex pheromone components of this species (Zhang et al. 1997). Three types of $P$. anxia male responders were identified: males that were captured principally in the 100:0 or 90:10 L-valine methyl ester/L- 
isoleucine methyl ester baited traps, those that were captured in the 0:100 L-valine methyl ester/L-isoleucine methyl ester baited traps, and those that were captured in traps baited with blends $(90: 10,80: 20,60: 40,40: 60,20: 80$, 10:90) of the two compounds (Fig. 1). No morphological characters were found that delineated these populations (Robbins, personal observation). Males captured with intermediate blends of L-valine methyl ester/L-isoleucine methyl ester were found only in populations from south-
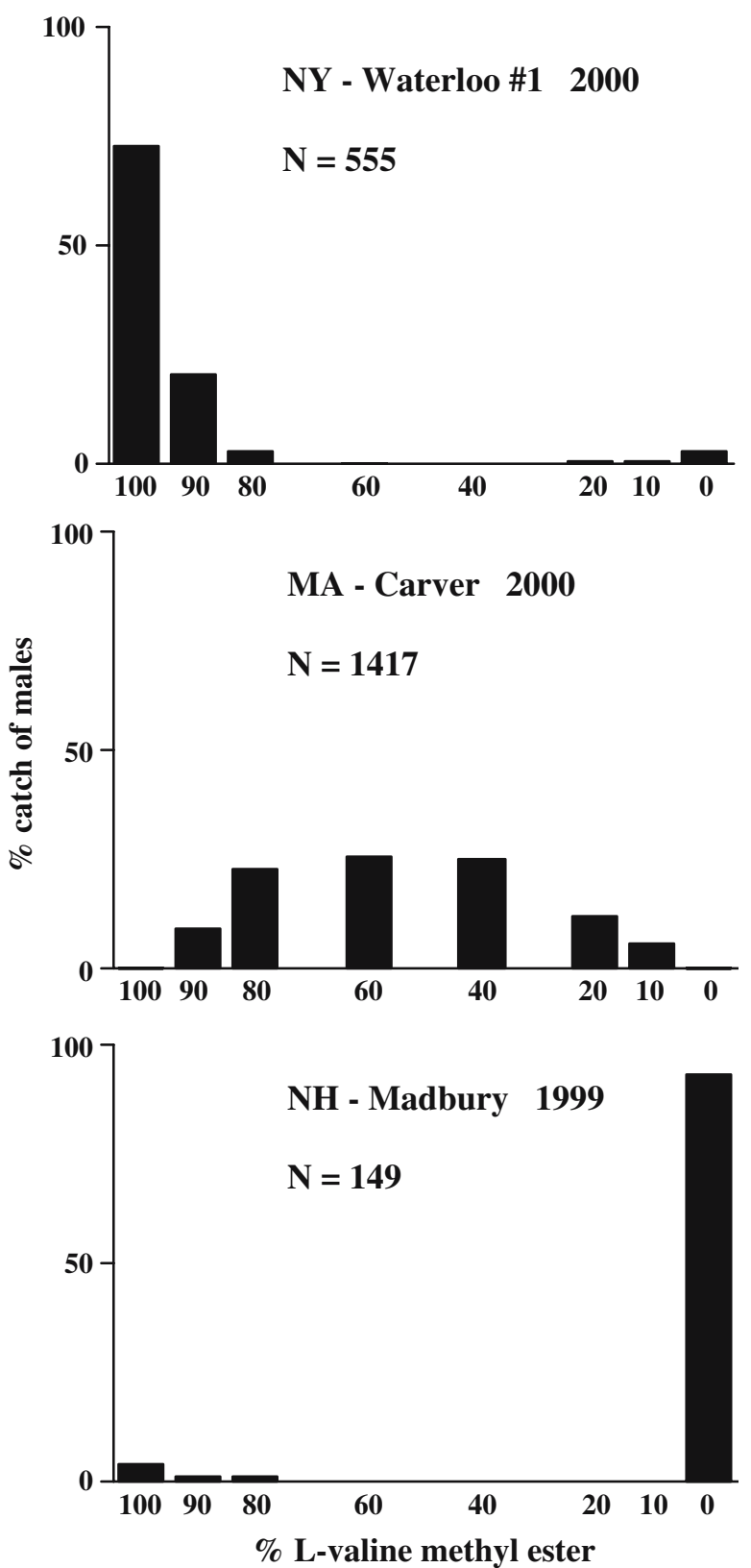

Fig. 1 Captures of male $P$. anxia in traps baited with various blends of the methyl esters of L-valine and L-isoleucine at three different sites. Captures for each lure blend are shown as a percentage of the total catch at that site eastern Massachusetts and Rhode Island, whereas the groups responding to predominantly L-valine methyl ester or L-isoleucine methyl ester alone were captured over a much greater area (Fig. 2). In most locations, either the Lvaline methyl ester population or the L-isoleucine methyl ester population dominated the male flight response profile, but at several sites, both populations occurred in large numbers flying on the same dates, producing a bimodal trap response profile (e.g., Fig. 3).

To investigate these populations in greater detail, experiments were conducted at three sites. At the first site, near Franklinville, NY, sex pheromone glands from individual females were analyzed to determine whether the female pheromone production curve was also bimodal. Male capture-mark-release-recapture studies were also conducted at Franklinville to determine repeatability of male preference. At the second site, near Carver in southeastern Massachusetts, where males responded to the various blend combinations, the range of ratios of L-valine methyl ester/ L-isoleucine methyl ester produced by females was determined, to compare with the male response curves. The third site, Waterloo \# 1 (Robbins et al. 2006), near Geneva, NY, was used to test the role of L-isoleucine methyl ester as a minor component in an L-valine methyl ester-responding $P$. anxia population.

\section{Methods and Materials}

Franklinville, NY-Single Female Pheromone Gland Analysis Female $P$. anxia were captured with UV light traps at the Franklinville site in 2000 to determine whether the ratios of L-valine methyl ester/L-isoleucine methyl ester produced by females mirrored the bimodal nature of the male response profile recorded in 1999 (Fig. 3). Five light traps were maintained at the site in 2000 from May 1 to June 30. Each day, insects captured in light traps were retrieved, and the sexes were separated. Females were stored individually in $\sim 30-\mathrm{ml}$ plastic cups in a 3:1 mix of greenhouse sand and screened peat moss raised to approximately $12 \%$ moisture. Each cup was marked with the date and light trap identification number. Cups containing females were held in a home refrigerator for 2-3 d and then at $10^{\circ} \mathrm{C}$ for up to $4 \mathrm{~d}$ until gland contents were extracted for analysis. Pheromone glands were everted by applying gentle pressure to the abdomen and then excised with iris scissors. Excised glands were soaked individually for $20 \mathrm{~min}$ in $200 \mu \mathrm{l}$ of dichloromethane, removed, and the extract concentrated under a nitrogen stream to approximately $20 \mu \mathrm{l}$. Samples were stored at $-80^{\circ} \mathrm{C}$ until analysis.

Single-gland analysis of the Franklinville females was carried out by using a coupled gas chromatographelectroantennogram detector (GC-EAD). A Hewlett-Packard 
Fig. 2 Captures of male $P$. anxia, northern genitalic form, in traps baited with various blends of the methyl esters of L-valine and L-isoleucine. Total male capture $=20,640$. Catches from all years are not shown here. $X$ - and $Y$-axes are the same as those shown in Fig. 1

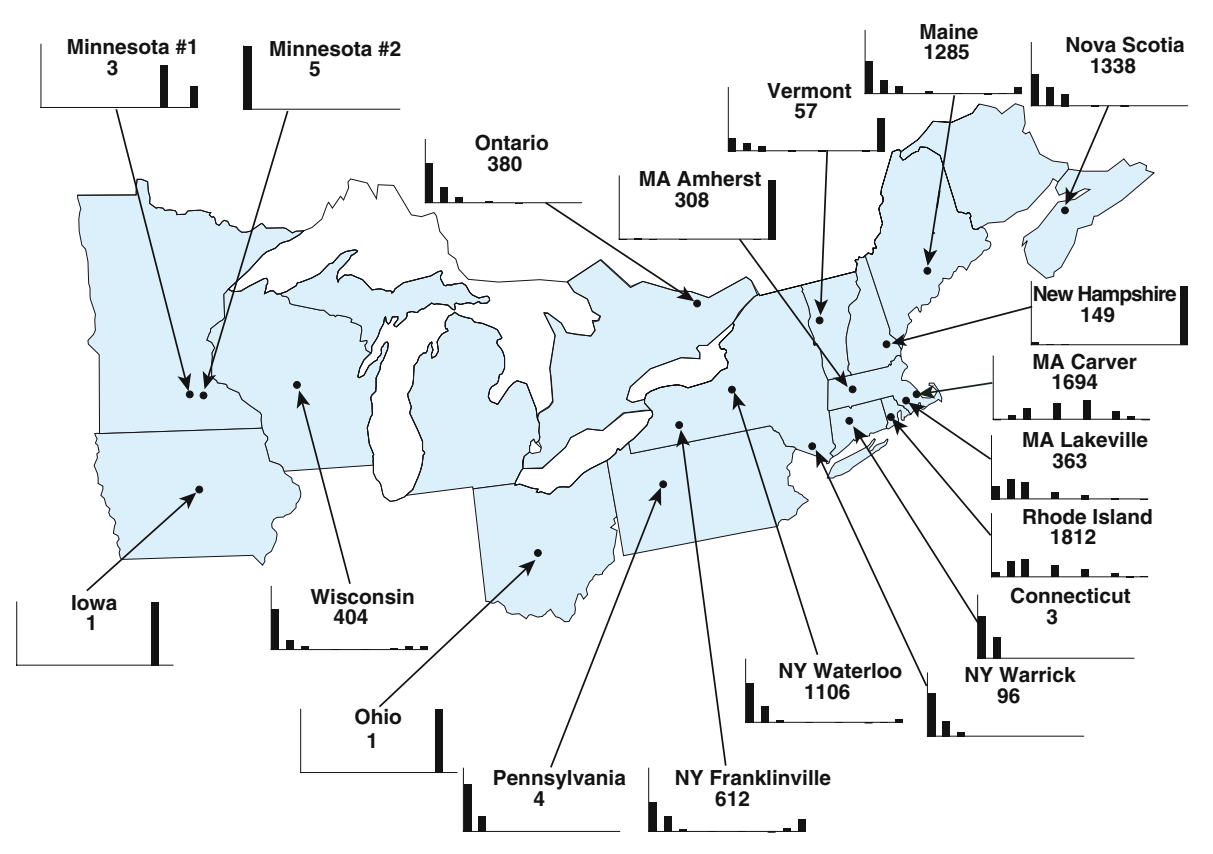

5890 series II gas chromatograph equipped with a nonpolar EC-1 Econo-Cap column $(30 \mathrm{~m} \times 0.25 \mathrm{~mm}$ inner diameter [ID], $0.25 \mu \mathrm{m}$ film thickness; Alltech, Deerfield, IL) was used for the analyses. The carrier gas was $\mathrm{N}_{2}$ at a head pressure of $138 \mathrm{kPa}$ (flow rate, $2.0 \mathrm{ml} / \mathrm{min}$ ). Injections were made in splitless mode (split valve opened at $1 \mathrm{~min}$ ). The temperature program was $40^{\circ} \mathrm{C}$ for $5 \mathrm{~min}$, then $15^{\circ} \mathrm{C} / \mathrm{min}$ to $250^{\circ} \mathrm{C}$, and held for $10 \mathrm{~min}$. Injector, EAD outlet, and flame ionization detector (FID) temperatures were $250^{\circ} \mathrm{C}$. The column effluent was combined with $\mathrm{N}_{2}$ makeup gas (30 $\mathrm{ml} / \mathrm{min})$ and then split 1:1 to the FID and EAD.

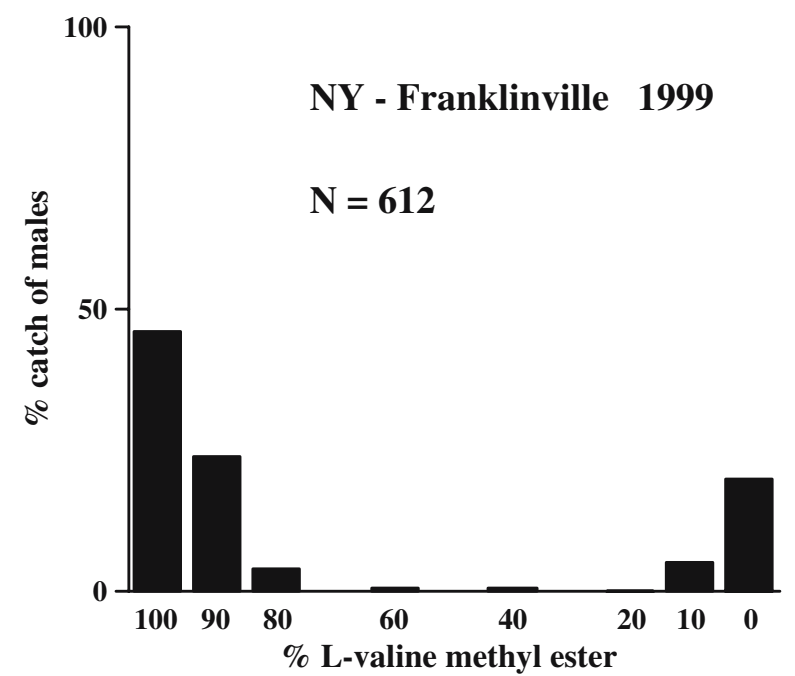

Fig. 3 Captures of male $P$. anxia in traps baited with various blends of the methyl esters of L-valine and L-isoleucine at a bimodal site. Captures for each lure blend are shown as a percentage of the total catch at that site
An extra FID port of the GC was modified and used for the EAD outlet. The EAD transfer line was terminated in a humidified, filtered air stream, which was cooled by a modified condenser flushed with $0^{\circ} \mathrm{C}$ water. The air stream carried the column effluent over the beetle antennal preparation. See Robbins et al. (2003) for a photograph of the beetle antennal preparation. The output signal from the antenna was amplified by a customized single-step highinput impedance DC amplifier. The resulting signal was recorded on a HP 3390 A integrator synchronized with the GC integrator. These methods were adapted from Nojima et al. (2003a) and Zhang et al. (1997).

Pheromone glands from 67 Franklinville females were extracted and analyzed by GC-EAD in 2000, using antennae from 11 different males. Preliminary work indicated no differences in antennal responses between the races when antennae from males of each of the two races were tested in the GC-EAD apparatus with $1 \mu$ of a hexane solution containing $1 \mathrm{ng} / \mu \mathrm{l}$ of the methyl esters of L-valine and L-isoleucine.

Franklinville, NY-Male Capture-Mark-Release-Recapture Males of populations in Franklinville, NY, were studied from 2000 to 2002 using capture-mark-release-recapture methods to evaluate blend response specificity. Traps were deployed on May 1, before $P$. anxia flights began, and checked each day until flight activity ceased at the end of June. In 2000 and 2001, the blends of L-valine methyl ester/ L-isoleucine methyl ester were tested in the same ratios (100:0, 90:10, 80:20, 60:40, 40:60, 20:80, 10:90, and $0: 100$ ) and the same doses (4 mg per septum) as in the 1999 field test. A trap baited with a control septum treated with hexane was deployed in both years. A.C. Oehlschlager 
(ChemTica Internacional S.A. [San Jose, Costa Rica]) kindly provided the lures for this study. The traps (see Robbins et al. 2006) were placed at the edge of a mature hardwood forest bordering a large field. Traps were hung on metal stakes $\sim 15 \mathrm{~m}$ apart such that the trap bottom was $\sim 30 \mathrm{~cm}$ from the ground. Traps were rerandomized each morning after collecting the beetles. In 2000 and 2001, male beetles were collected from each trap/blend combination and marked with a unique paint (Testor Corporation, Rockford, IL) code identifying the date captured and the blend to which the male responded. Marked individuals were distributed randomly among three release sites and allowed to burrow into the soil. The three release sites were $20 \mathrm{~m}$ from the trap line and equidistant from each other. Data from recaptured males were recorded, and males were frozen for later identification to species.

In 2002, eight traps were deployed at the same site, consisting of four traps baited with lures containing $4 \mathrm{mg}$ of L-valine methyl ester and four containing $4 \mathrm{mg}$ of Lisoleucine methyl ester. Positions of the L-valine methyl ester and L-isoleucine methyl ester traps were alternated within the trap line at initial placement. Beetles were collected, and trap positions were rotated each day during the flight period. Beetles captured were marked according to the compound to which they responded and released as in 2000 and 2001. Data from recaptured males were recorded, and males were frozen for later identification to species.

Carver, MA-Analysis of Female Pheromone Gland Contents Virgin females were dug from a cranberry bog in Carver, MA, in April of 2001 and 2002 before the beetle flight season. This was the same bog from which the individuals used to identify the $P$. anxia sex pheromone were acquired (Zhang et al. 1997). In the laboratory, females were housed in glass observation cages in a controlled environment room maintained at $25^{\circ} \mathrm{C}$ during the $16-\mathrm{hr}$ photophase and $20^{\circ} \mathrm{C}$ during the 8 -hr scotophase. Cages contained a 3:1 mix of greenhouse sand and screened peat moss raised to approximately $12 \%$ moisture in the bottom (approximately $10 \mathrm{~cm}$ deep) in which the females could burrow. A 6-mm mesh wire screening was available for the females to climb on and call from during scotophase. When females were observed calling (Leal et al. 1993; Nojima et al. 2003b) during scotophase, they were removed from the cages, the glands were excised and extracted, and the extracts were stored as described previously. Samples were analyzed on a Shimadzu GC17A in splitless mode, equipped with a nonpolar EC-1 Econo-Cap column $(30 \mathrm{~m} \times 0.25 \mathrm{~mm}$ ID, $0.25 \mu \mathrm{m}$ film thickness; Alltech). Nitrogen was used as the carrier gas. During the 1-min time for splitless injection, the column head pressure was kept at $150 \mathrm{kPa}$ (flow rate, $2.2 \mathrm{ml} / \mathrm{min}$ ) and then decreased to $78 \mathrm{kPa}$ after the split valve was opened (flow rate, $1 \mathrm{ml} / \mathrm{min}$ ). The oven temperature was kept at $40^{\circ} \mathrm{C}$ for $2 \mathrm{~min}$, then programmed at $15^{\circ} \mathrm{C} / \mathrm{min}$ to $150^{\circ} \mathrm{C}(0 \mathrm{~min})$ and then at $30^{\circ} \mathrm{C} / \mathrm{min}$ to $250^{\circ} \mathrm{C}(8 \mathrm{~min})$. Injector and detector temperatures were 200 and $260^{\circ} \mathrm{C}$, respectively. A 1:1 mix of L-valine methyl ester and Lisoleucine methyl ester at a concentration of $10 \mathrm{ng} / \mu \mathrm{l}$ each in hexane was used to calibrate the instrument and determine retention times of the two compounds. Ratios of the two compounds were determined by manual integration of the electronically stored peaks. Individuals were then ranked in 5\% increments by percent of L-valine methyl ester from 0 to $100 \%$. For example, an individual with $14.8 \%$ L-valine methyl ester was placed in the $10 \%$ rank, whereas an individual with $16.3 \%$ L-valine methyl ester was placed in the $15 \%$ rank.

Waterloo, NY_Role of L-Isoleucine Methyl Ester as a Minor Component The male flight response profile at Waterloo \# 1 over several years (Robbins et al. 2006) indicated the presence of a large population that responded to lure blends containing a high percentage of L-valine methyl ester. This population provided an excellent site to test the effect on male capture of small amounts of L-isoleucine methyl ester added to the L-valine methyl ester. Traps were placed at the Waterloo no. 1 site, near Geneva, NY, on May 18, 2001 and removed on June 8, 2001. Treatments included L-valine methyl ester/L-isoleucine methyl ester blends of 100:0, 99.75:0.25, 99.5:0.5, 99:1, 97:3, 95:5, 90:10, and a solvent control-baited trap. Red rubber septa $(5 \mathrm{~mm}$ Thomas Scientific, Swedesboro, NJ) were loaded with $4 \mathrm{mg}$ each of the above blends by dissolving neat compounds in hexane, applying appropriate amounts to the septa, and allowing the hexane to evaporate in a fume hood. Three replications of the eight treatments were placed in three noncontiguous lines at the study site as described above. Traps were rerandomized each time they were checked, three times each week.

Statistics Data were tested for homogeneity of variance using Levene's test and log transformed $(x+1)$ if necessary. Data were analyzed with a one-way analysis of variance, $P<0.05$. Fisher's least significant difference test was used for post-hoc comparisons.

\section{Results}

Franklinville, NY_Analysis of Pheromone Glands of Females Of the 67 glands analyzed from females caught in light traps at the Franklinville site in 2000, 63 glands contained enough material for GC analysis. The pheromone blend ratios were partitioned into two groups: those with L-valine 
methyl ester/L-isoleucine methyl ester blends of approximately greater than 99:1 and those producing blends of approximately less than 1:99, yielding an unequivocal bimodal distribution (Fig. 4). In examining the coupled GC-EAD traces, it was found that in every instance, female glands contained both esters, regardless of the group to which they had been assigned. However, the amount of the lesser compound was often too small to be detected by the GC. Nevertheless, the EAD provided evidence of the presence of trace amounts of these compounds (Fig. 5).

Franklinville, NY-Capture-Mark-Release-Recapture of Males In capture-mark-release-recapture experiments of males, the rate of recapture for 2000 was $13.1 \%$ (39 of 297; Fig. 6a) and for 2001 was $10.9 \%$ (32 of 293; Fig. 6b). In both 2000 and 2001, males captured in traps baited with blends containing a high proportion of L-valine methyl ester were recaptured in traps baited with those blends. The shapes of the male recapture profiles are nearly identical to those of the capture profiles. In neither year were any males that were captured in the $100 \%$ L-isoleucine methyl esterbaited trap recaptured in that trap. In 2001, a single male captured using $100 \%$ L-isoleucine methyl ester returned to the $100 \%$ L-valine methyl ester-baited trap.

In 2002, the capture-mark-release-recapture field trial was redesigned. Because no males were recaptured in traps baited with the $100 \%$ L-isoleucine methyl ester in 2000 or 2001, we hypothesized that the sensitivity of the Lisoleucine methyl ester-responding population to the large amount of L-valine methyl ester emanating from the other blends present at the trapping site hindered their recapture in the single $100 \%$ L-isoleucine methyl ester-baited trap. The response curve of males from Franklinville in 1999

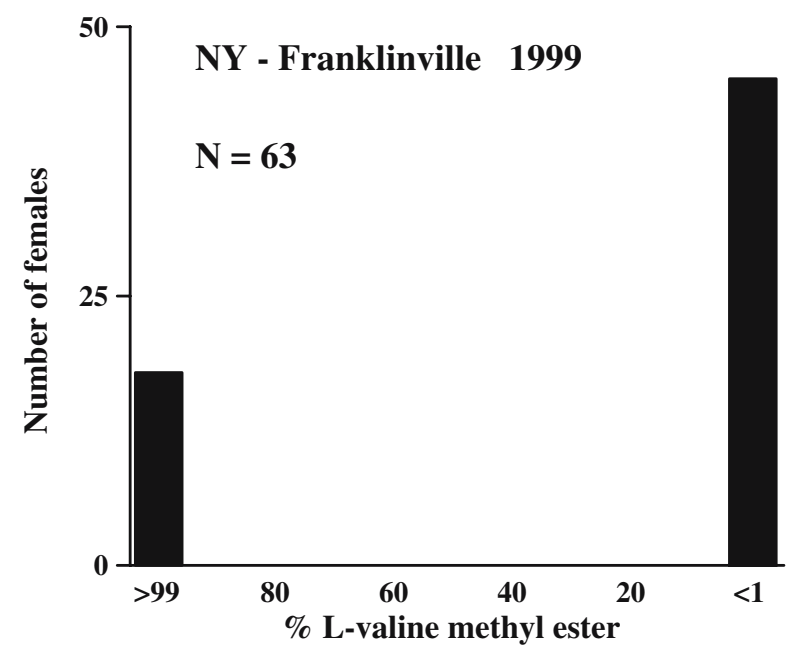

Fig. 4 Percentages of the methyl esters of L-valine and L-isoleucine extracted from pheromone glands of female P. anxia, Franklinville, NY, 2000

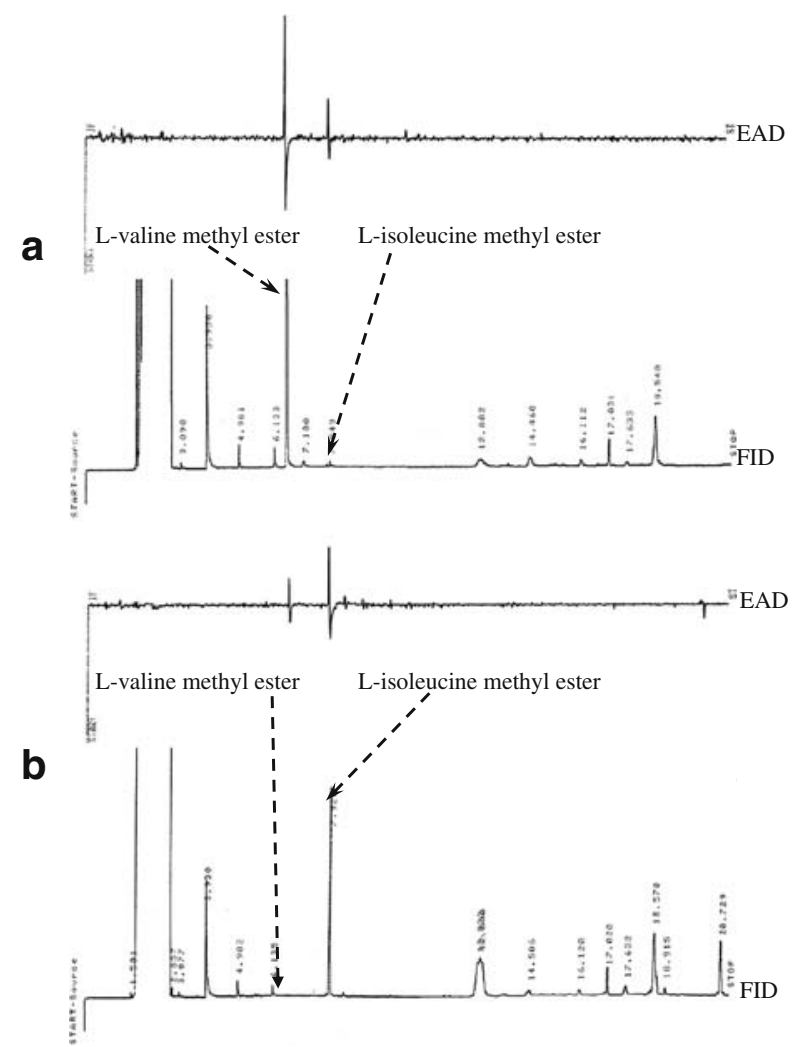

Fig. 5 Simultaneous EAD and FID traces illustrating male antennal responses to the gland contents of the two populations of female $P$. anxia found at Franklinville, NY, 2000. a L-Valine methyl ester population; b L-isoleucine methyl ester population

(Fig. 3) revealed that the population that responded to the high-percentage L-valine methyl ester blends was more tolerant of the presence of L-isoleucine methyl ester than was the L-isoleucine methyl ester-responding population to the presence of L-valine methyl ester. This phenomenon was also true for other $P$. anxia response profiles, whether or not both populations were present at a given site (Robbins et al. 2006). Bearing these observations in mind, males used for capture-mark-release-recapture in 2002 were presented with only the two pure compounds, $100 \%$ L-valine methyl ester and $100 \%$ L-isoleucine methyl ester. The capture profile of males in 2002 (Fig. 6c) indicated an increase in the number of beetles captured in the L-isoleucine methyl ester-baited traps relative to 2000 or 2001 . The total rate of recapture for 2002 was $16.0 \%$ (212 of 1,320). The rate of recapture for the L-valine methyl ester-baited traps was $27.8 \%$ (199 of 717) and for the L-isoleucine methyl ester baited traps was $2.1 \%$ (13 of 603). A single male captured in a L-valine methyl ester-baited trap was recaptured in a L-isoleucine methyl ester-baited trap.

Carver, MA-Analysis of Pheromone Gland Contents of Females The contents of pheromone glands from 21 females were analyzed during 2001 and 2002. Of these, 17 
Fig. 6 P. anxia male capturemark-release-recapture in traps baited with various blends of the methyl esters of $\mathrm{L}$-valine and L-isoleucine. Franklinville, NY, a 2000, b 2001, c 2002. Graph on the left indicates percent male capture in each blend. Graph on the right indicates the percent female recapture in a given blend and the blend from which it was first captured in the graph on the left
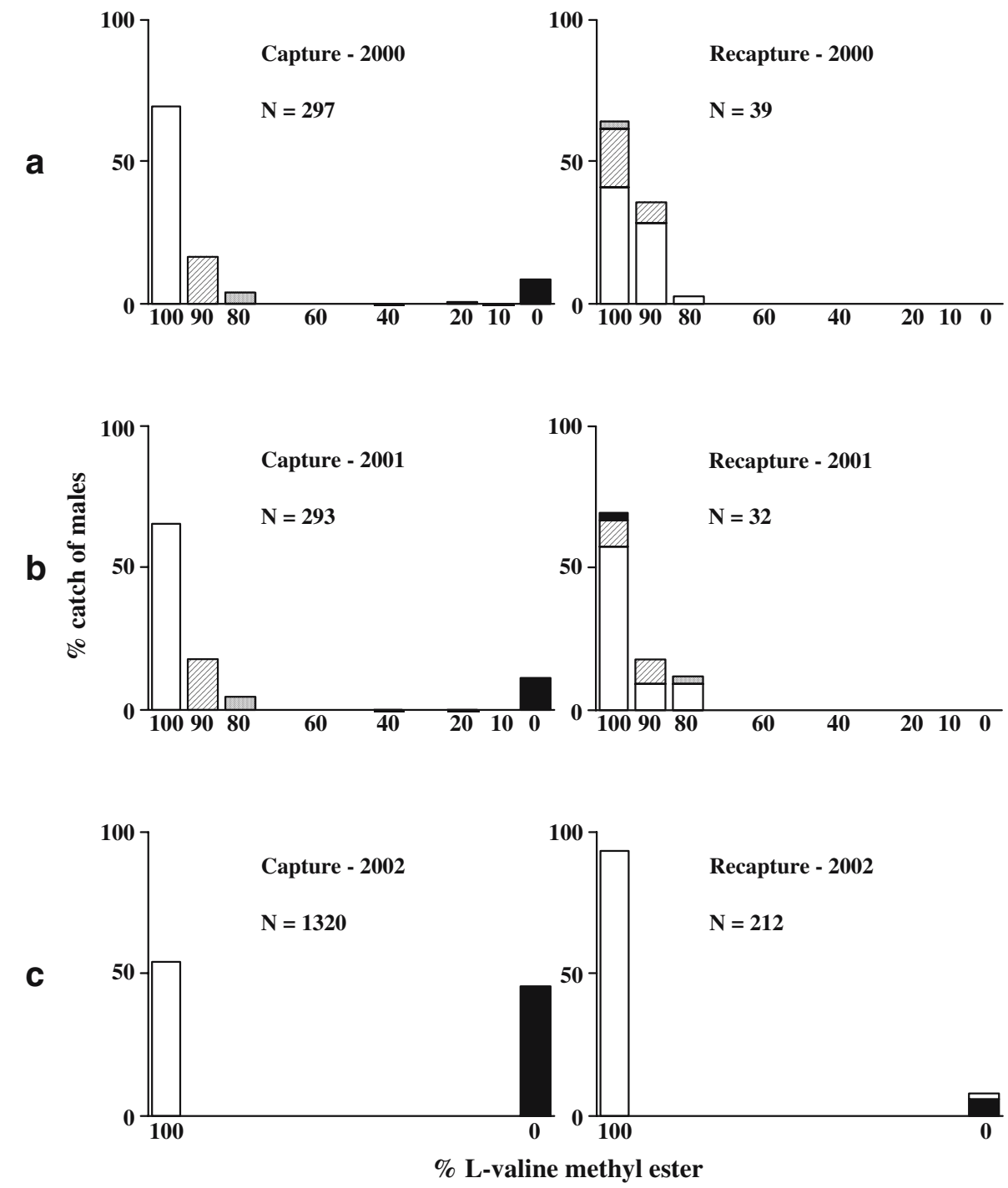

extracts had sufficient amounts of the two components to calculate blend ratios. Single-gland analyses of females from the Carver site yielded a histogram of L-valine methyl ester/L-isoleucine methyl ester ratios (Fig. 7) similar to the male response curve found there in 1999 (Fig. 1) as well as other years (Robbins et al. 2006). No females from the Carver site produced blends of greater than 99:1 L-valine methyl ester/L-isoleucine methyl ester or less than 1:99, resembling those from Franklinville, NY. Of the 7,004 male P. anxia captured at Carver, MA, over 4 yr of trapping, only 33 were captured in the $100 \%$ L-valine methyl ester-baited traps and 22 in the $100 \%$ L-isoleucine methyl ester-baited traps. Thus, more than $99 \%$ of the males captured at Carver, MA, were captured using blends of the two compounds.

Waterloo, NY-Role of L-isoleucine Methyl Ester as a Minor Component All baited traps captured significantly $\left(F_{7,16}=\right.$ 8.43; $P<0.001)$ more males than the control (hexane only)

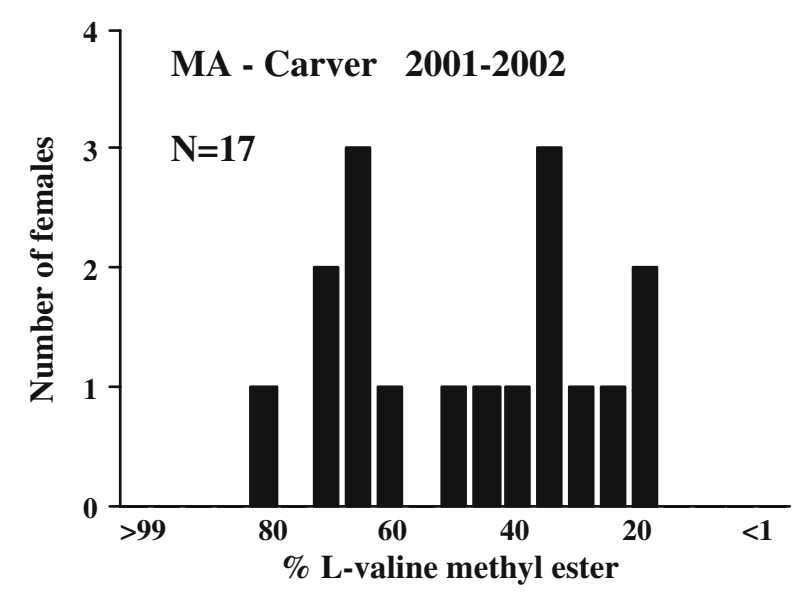

Fig. 7 Percentages of the methyl esters of L-valine and L-isoleucine extracted from pheromone glands of female P. anxia, Carver, MA, 2001 and 2002 


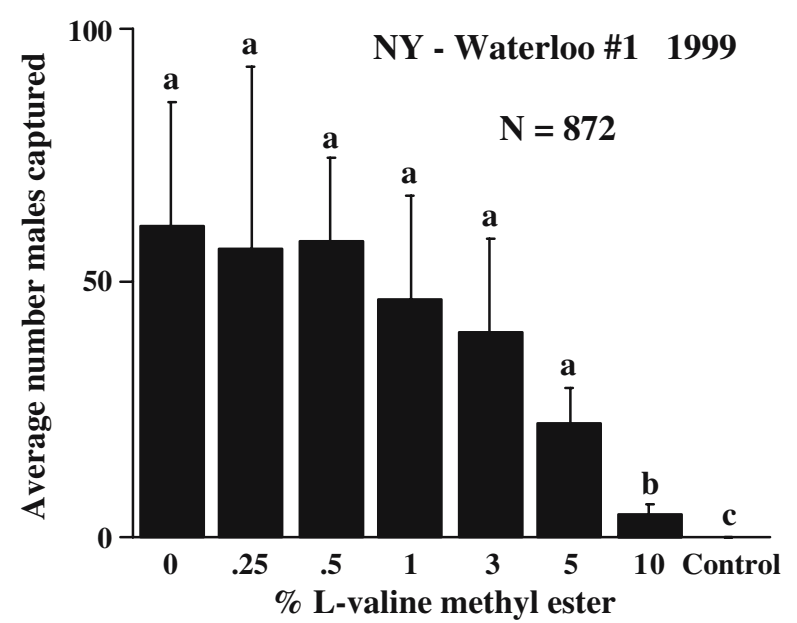

Fig. 8 Average capture/treatment (mean \pm SE) of male P. anxia in traps baited with various blends of the methyl esters of L-valine and Lisoleucine. Waterloo, NY, 2001. Bars with the same letter are not significantly different, $P<0.05$, Fisher's LSD test

traps (Fig. 8). There were no significant differences in numbers of males captured in traps baited with $0,0.25,0.5$, $1.0,3.0$, and $5.0 \%$ L-isoleucine methyl ester (relative to the amount of L-valine methyl ester). The trap baited with $10 \%$ L-isoleucine methyl ester captured significantly fewer males than any of the traps baited with the other six blends with lower percentages of L-isoleucine methyl ester or no Lisoleucine methyl ester. Thus, we conclude that isoleucine did not function as a pheromone component at trace levels but rather was antagonistic at increasing doses.

Hand digging at Waterloo no. 1, NY, in April of 1999 yielded three virgin females. GC-EAD analysis of their pheromone gland contents showed a pattern identical to females from the Franklinville L-valine methyl ester group (Robbins, unpublished data), with large amounts of L-valine methyl ester and only trace amounts of L-isoleucine methyl ester.

\section{Discussion}

Evidence for Pheromone Races in P. anxia The results from analysis of female pheromone gland contents and capturemark-release-recapture field tests with males offer experimental evidence for the existence of three pheromone races of the northern genitalic form of $P$. anxia: one in which females produce and males respond mainly to L-valine methyl ester, a second that employs L-isoleucine methyl ester, and a third that produces and responds to an intermediate range of blends of the two compounds. The variation in the sex pheromone system of $P$. anxia stands in direct contrast to the intraspecific uniformity of male pheromone response profiles found for 23 other Phyllophaga species captured at more than one geographical location (Robbins et al. 2006).

At Franklinville, NY, pheromone gland contents of females were analyzed by using GC coupled with EAD. One fraction of the population produced greater than $99 \%$ L-valine methyl ester, whereas the other fraction produced greater than $99 \%$ L-isoleucine methyl ester. Capture-markrelease-recapture field tests of males at Franklinville established that most but not all males were recaptured in traps baited with the same ratios of compounds in which they were originally captured. In 2000 and 2001, the trap lures were 100:0, 90:10, 80:20, 60:40, 40:60, 20:80, 10:90, and 0:100 L-valine methyl ester/L-isoleucine methyl ester. The results from those trapping tests revealed that $94 \%$ of the males captured in the 100:0 and 90:10 combinations were recaptured in traps baited with those same mixtures. In 2002, traps were baited with L-valine methyl ester or Lisoleucine methyl ester alone. In that test, of the males recaptured, $99.5 \%$ captured initially in traps baited with $100 \%$ L-valine methyl ester were recaptured in traps baited with the same source, whereas $100 \%$ captured in traps baited with $100 \% \mathrm{~L}$-isoleucine methyl ester were recaptured in traps baited with $100 \%$ L-isoleucine methyl ester. Thus, the two P. anxia populations found at Franklinville, NY, are sympatric and synchronic, although it is unknown if they have different diel activity cycles.

Pheromone response curves of males resembling those of the two P. anxia pheromone races found at Franklinville, NY, are distributed from eastern Canada and the northeast USA to the north central USA (Fig. 2), sometimes in allopatry and sometimes in sympatry. Populations responding to blends have been found only in southeastern Massachusetts and Rhode Island. The blend responders appear as two groups. The first group, represented by a male capture profile generated from the Carver site (Fig. 9), was found at three locations (see the Carver, MA, and Plympton, MA, sites in Robbins et al. 2006) at which the overwhelming majority of males were captured in traps baited with blends of L-valine methyl ester/L-isoleucine methyl ester. Female P. anxia at Carver, MA, were found to produce blends of $\mathrm{L}$-valine methyl ester/L-isoleucine methyl ester that ranged from 16:84 to 79:21 (Fig. 7). The male response profiles generated from capture data at the Carver site (Fig. 9) overlapped female production profiles by about $10 \%$ at each end, suggesting that the male response window was wider than the range of blends produced by the Carver females. In $4 \mathrm{yr}$ of field testing at Carver, MA, and $1 \mathrm{yr}$ each at Plympton no. 1, MA, and no. 2, MA, a total of 7,717 male $P$. anxia were captured. Of this total, only 53 $(0.7 \%)$ were captured in traps baited with L-valine methyl ester alone, and $24(0.3 \%)$ were captured in traps baited with L-isoleucine methyl ester alone. 

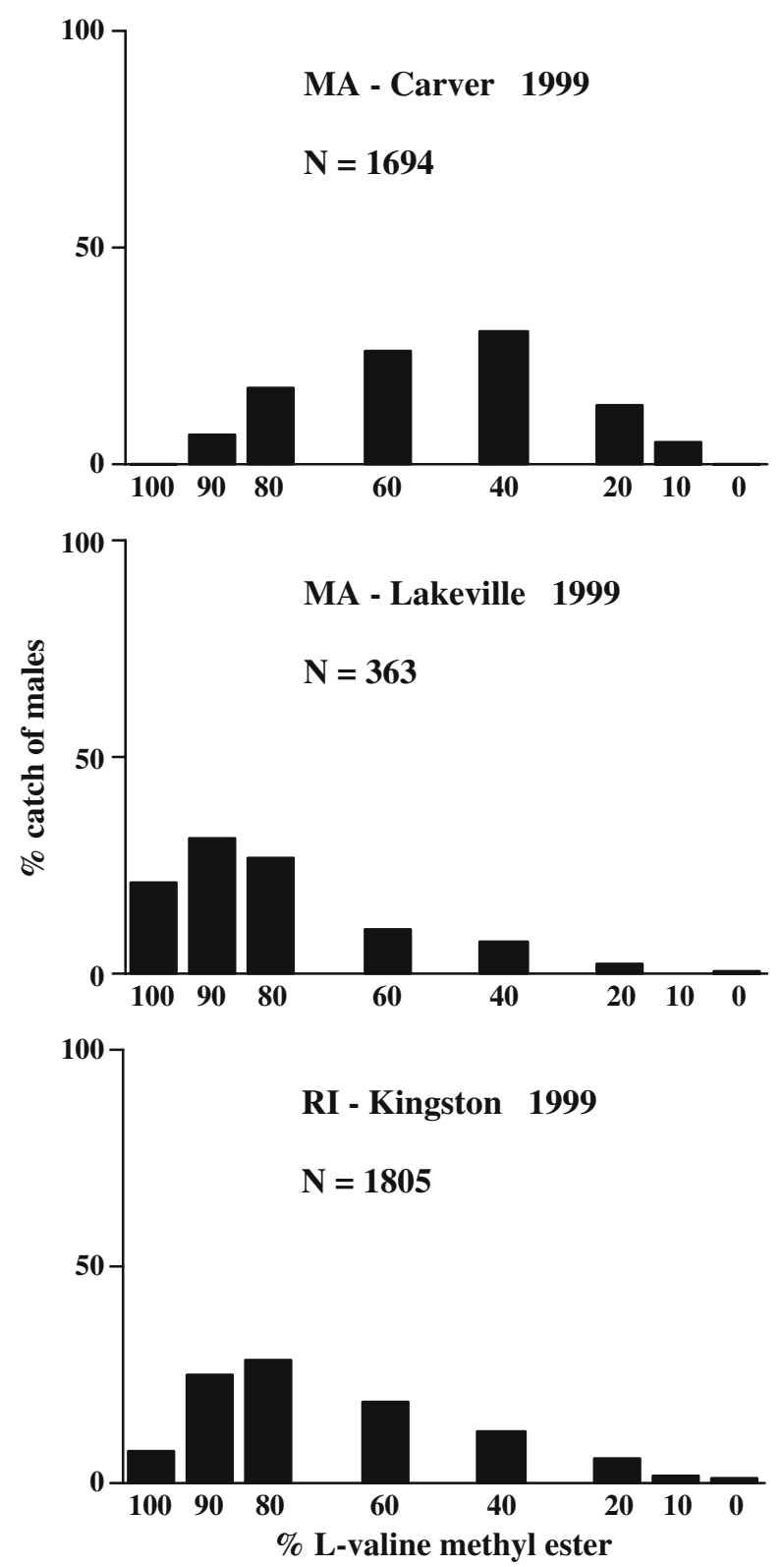

Fig. 9 Captures of male $P$. anxia in traps baited with various blends of the methyl esters of L-valine and L-isoleucine at test sites in southeast Massachusetts and Rhode Island. Captures for each lure blend are shown as a percentage of the total catch at that site

The second group responding to blends is represented by male capture profiles generated from $2 \mathrm{yr}$ of field testing at Lakeville, MA, and Kingston, RI (Fig. 9). Although the majority of males at these sites were captured in traps baited with blends of L-valine methyl ester/L-isoleucine methyl ester, male capture curves were shifted to the L-valine methyl ester end of the blends presented, relative to those noted at Carver, MA. At the Carver and Plympton sites, an average of $0.7 \%$ of the males were captured in traps baited with $100 \%$ L-valine methyl ester, but in Lakeville, MA, and
Kingston, RI, an average of $15.5 \%$ of the males were captured in traps baited with 100\% L-valine methyl ester.

Intraspecific Variation in Insect Sex Pheromone Systems Sex pheromone variation is well documented in numerous insect species (Löfstedt 1990; Phelan 1997), particularly those in the order Lepidoptera. The turnip moth, Agrotis segetum, is widely distributed throughout Europe, the near East, and Africa. Various ratios of (Z)-5-decenyl acetate, (Z)-7-dodecenyl acetate, and (Z)-9-tetradecenyl acetate were required to attract males throughout Eurasia and North Africa, whereas in sub-Saharan Africa, (Z)-5-decenyl acetate alone attracted males (Arn et al. 1983; Löfstedt et al. 1986; Tóth et al. 1992; Wu et al. 1999). The larch budmoth, Zeiraphera diniana, consists of two host races that feed on larch and Cembran pine in the European Alps. The host races exist in both allopatry and sympatry, with each race producing and responding to its own pheromone. Cembran pine populations of $Z$. diniana utilize $(E)$-9-dodecenyl acetate as their pheromone, whereas the larch populations utilize (E)-11-tetradecenyl acetate (Baltensweiler et al. 1978; Baltensweiler and Priesner 1988). In contrast, analyses of populations of the pink bollworm moth, Pectinophora gossypiella, sampled in several areas of the world (Haynes and Baker 1988), and the cabbage looper moth, Trichoplusia ni, sampled across the USA (Haynes and Hunt 1990), demonstrated little variation in female produced pheromone blends.

The first case of intraspecific geographical variation in sex pheromone response was demonstrated in the Coleoptera. Lanier et al. (1972) utilized pine bolts infested with male pine engraver (Ips pini) from California, Idaho, and New York to perform reciprocal field tests at each of the three locations. In New York, beetles responded much more strongly to the infested bolts from New York than to either the infested bolts from California or Idaho. In both California and Idaho, the local populations preferred infested bolts from Idaho over bolts from California. In California, the local population showed only a small response to the New York bolts. Lanier et al. (1980) quantified ratios of (+)- and (-)-ipsdienol from I. pini males from Idaho and New York and field tested the two compounds in both locations. They concluded that the differences in production of and response to the enantiomers of ipsdienol in the populations at each of the locations explained their earlier work with infested bolts. Later, Miller et al. (1989) demonstrated that both chirality and quantity of the enantiomers of ipsdienol varied both between and within populations, even populations as close in proximity as southwestern and southeastern British Columbia.

The sex pheromone variation observed in $P$. anxia resembles none of the examples described above but rather 
is reminiscent of the patterns seen in the European corn borer, Ostrinia nubilalis. In $O$. nubilalis, two pheromone races use blends of $(E)$-11-tetradecenyl acetate and (Z)-11tetradecenyl acetate. The $E$ race produces a 99:1 blend of $E / Z$ isomers, whereas the $Z$ race produces a 3:97 blend of $E / Z$ isomers. In the field, these races occasionally mate, and hybrids are produced. Hybrid females produce intermediate blend ratios of approximately 35:65 Z/E (Roelofs et al. 1985; Glover et al. 1991), and hybrid male moths preferentially fly to blends of the $E / Z$ isomers in the flight tunnel, although more hybrid males of either $E \times Z$ or $Z \times E$ crosses fly to the $Z$ blend alone than to the $E$ blend alone. Despite of the fact that natural hybridization between the $E$ and $Z$ pheromone races is well documented in the field, an in-depth genetic analysis of sex pheromone production and perception in this species predicts that no self-sustaining population of hybrids can exist (Roelofs et al. 1987). Therefore, the origin of the stable blend-responding populations of $P$. anxia is intriguing.

In $O$. nubilalis, the differences in the blend ratios of $(E)$ and (Z)-11-tetradecenyl acetate are due to a single change in the activity of the reductase enzyme that determines the final blend ratio in pheromone production (Linn and Roelofs 1995). Roelofs et al. (1987) speculated that a few simple genetic substitutions could result in the $E$ strain evolving from the $Z$ strain. However, changes in the sex pheromone production system would have to evolve by a different mechanism in $P$. anxia because the raw materials are not synthesized de novo. L-Valine and L-isoleucine are essential amino acids (Chapman 1982) and must either be sequestered during larval feeding or produced by bacterial endosymbionts. Our results from Franklinville showed that both amino acid methyl esters were present in the female pheromone glands of females, one in large amounts and the other in very small amounts, whereas at Carver, the compounds were present in the pheromone glands of females in intermediate blends. Therefore, the titers of the amino acids before esterification or the formation of the methyl esters themselves must be regulated in some manner in all the pheromone races. If bacteria are involved in production of sex pheromones in $P$. anxia, as they are in Costelytra zealandica, another melolonthine scarab beetle (Henzell and Lowe 1970; Hoyt and Osborne 1971), their identification and coevolution with the many Phyllophaga species will be of interest.

Genitalic Morphology and Pheromone Races in P. anxia Although this study was undertaken to examine the sex pheromone variation encountered in the northern genitalic form of $P$. anxia, this discussion would not be complete without including mention of the southern genitalic form. Luginbill and Painter (1953) note that $P$. anxia, the most widely distributed Phyllophaga species in
North America, is a variable species in both size and genitalic characters. In an examination of $P$. anxia from collections at Rutgers University, the University of Kentucky, and the University of Alabama, Robbins found both distinctly northern and southern forms of genitalia from each of the three states, as well as genitalic forms that can be regarded as intermediates (Robbins, unpublished data). Luginbill and Painter (1953) also record the presence of intermediate forms. The southern form has been captured only in traps baited with $100 \%$ L-isoleucine methyl ester (Robbins et al. 2006). Although little is known about close range courtship and mating behaviors in Phyllophaga, there is nothing that precludes a male of the southern genitalic form flying upwind to a female of the northern genitalic form producing L-isoleucine methyl ester or vice versa. Successful matings between northern and southern forms may explain the existence of intermediate genitalic phenotypes.

Acknowledgments P.S.R. thanks Satoshi Nojima and Bruce Morris for generously sharing their knowledge of GC-EAD and chemistry techniques. We thank Donna Boyce of Communication Services at Cornell University in Geneva, NY, for assistance with illustrations. P.S.R. also thanks Michael G. Villani, friend, mentor, and committee chair, who passed away on May 15, 2001.

\section{References}

Arn, H., Esbjerg, P., Bues, R., Tóth, M., SzÖcs, G., Guerin, P., and AUSCHER, S. 1983. Field attraction of Agrotis segetum males in four European countries to mixtures containing three homologous acetates. J. Chem. Ecol. 9:267-276.

Baltensweiler, V. W., and Priesner, E. 1988. A study of pheromone polymorphism in Zeiraphera diniana Gn. (Lep., Tortricidae). 3. Specificity of attraction to synthetic pheromone sources by different male response types from two host races. J. Appl. Entomol. 106:217-231.

Baltensweiler, V. W., Priesner, E., Arn, H., and Delucchi, V. 1978. Evidence for different sexual attractants used by the larch form and cembran pine form of the gray larch bud moth Zeiraphera diniana. Mitt. Schweiz. Entomol. Ges. 51:133-142.

Chapman, R. F. 1982. The Insects: Structure and Function. Harvard University Press, Cambridge, MA.

DitTL, T. G., and Kummer, L. D. 1997. Major Cranberry Insect Pests of Wisconsin. www.wiscran.org/cranbugs.pdf.

Evans, A. V., and Smith, A. B. T. 2007. An Electronic Checklist of the New World Chafers (Coleoptera: Scarabaeidae: Melolonthinae), Version 2. Ottawa, Canada. 349 pp. http://www.museum.unl.edu/ research/entomology/nwmelos.htm.

FranKLIN, H. J. 1950. Cranberry Insects of Massachusetts. Bulletin 445. Parts II-VII. Massachusetts Agricultural Experimental Station, Amherst, MA.

Glover, T. J., Knodel, J. J., Robbins, P. S., Eckenrode, C. J., and RoELOFS, W. L. 1991. Gene flow among three races of European corn borers (Lepidoptera: Pyralidae) in New York state. Env. Entomol. 20:1356-1362.

HAYNES, K. F., and BAKER, T. C. 1988. Potential for evolution of resistance to pheromones. Worldwide and local variation in chemical communication system of pink bollworm moth, Pectinophora gossypiella. J. Chem. Ecol. 14:1547-1560. 
HAYNES, K. F., and HunT, R. E. 1990. Interpopulational variation in emitted pheromone blend of cabbage looper moth, Trichoplusia ni. J. Chem. Ecol. 16:509-519.

Henzell, R. F., and Lowe, M. D. 1970. Sex attractant of the grass grub beetle. Science 168:1005-1006.

HoYT, C. P., and OsBorNe, G. O. 1971. Production of an insect sex attractant by symbiotic bacteria. Nature 230:472-473.

LANiER, G. N., BIRCH, M. C., SChMitZ, R. F., and FurNiss, M. M. 1972. Pheromones of Ips pini (Coleoptera: Scolytidae): variation in response among three populations. Can. Entomol. 104:1917-1923.

Lanier, G. N., Classon, A., Stewart, T., Piston, J. J., and SILVERSTEIN, R. M. 1980. Ips pini: The basis for interpopulational differences in pheromone biology. J. Chem. Ecol. 6:677-687.

Leal, W. S., Sawada, M., Matsuyama, S., Kuwahara, Y., and HASEGAWA, M. 1993. Unusual periodicity of sex pheromone production in the large black chafer Holotrichia parallela. J. Chem. Ecol. 19:1381-1391.

LiNN, C. E., and RoElofs, W. L. 1995. Pheromone communication in moths and its role in the speciation process, pp. 263-300, in D. M. Lambert, and H. G. Spencer (eds.). Speciation and the Recognition Concept The Johns Hopkins University Press, Baltimore, MD.

LÖFSTEDT, C. 1990. Population variation and genetic control of pheromone communication systems in moths. Entomol. Exp. Appl. 54:199-218.

Löfstedt, C., Löfqvist, J., Lanne, B. S., Van Der Pers, J. N. C., and HANSSON, B. S. 1986. Pheromone dialects in European turnip moths Agrotis segetum. Oikos 46:250-257.

LuginBiLl, P., and PAINTER, H. R. 1953. May Beetles of the United States and Canada. US Department of Agriculture Technical Bulletin no. 1040.

Miller, D. R., Borden, J. H., and Slessor, K. N. 1989. Inter- and intrapopulation variation of the pheromone, ipsdienol produced by male pine engravers, Ips pini (Say) (Coleoptera: Scolytidae). J. Chem. Ecol. 15:233-248.

Nojima, S., Linn, C. E. , Morris, B. D., Zhang, A., and Roelofs, W. L. 2003a. Identification of host fruit volatiles from hawthorn (Crataegus spp.) attractive to hawthorn-origin Rhagoletis pomonella flies. J. Chem. Ecol. 29:319-334.

Nojima, S., Robbins, P. S., SAlsbury, G. A., Morris, B. D., RoelofS, W. L., and Villani, M. G. 2003b. L-Leucine methyl ester: The female-produced sex pheromone of the scarab beetle Phyllophaga lanceolata. J. Chem. Ecol. 29:2439-2446.

PHELAN, P. L. 1997. Evolution of mate-signaling in moths: phylogenetic considerations and predictions from the asymmetric tracking hypothesis, pp. 240-256, in J. C. Choe, and B. J. Crespi (eds.). Mating Systems in Insects and ArachnidsCambridge University Press, Cambridge, MA.

Robbins, P. S., Crocker, R. L., Nojima, S., Morris, B. D., Roelofs, W. L., and Villani, M. G. 2003. Methyl 2- (methylthio)benzoate: the unique sulfur-containing sex pheromone of Phyllophaga crinita. Naturwissenschaften 90:517-520.

Robbins, P. S., Alm, S. R., Armstrong, C. D., Averill, A. L., BAKer, T. C., BAUERnFIEND, R. J., BAXENDale, F. P., Braman, S. K., Brandenburg, R. L., Cash, D. B., Couch, G. J., Cowles, R. S., Crocker, R. L., Delamar, Z. D., Dittl, T. G., FitZPatrick, S. M., Flanders, K. L., Forgatsch, T., GibB, T. J., Gill, B. D., Gilrein, D. O., Gorsuch, C. S., Hammond, A. M., Hastings, P. D., Held, D. W., Heller, P. R., Hiskes, R. T., Holliman, J. L., Hudson, W. G., Klein, M. G., KrischiK, V. L., LeE, D. J., LinN, C. E., Luce, N. J., Mackenzie, K. E., Mannion, C. M., Polavarapu, S., Potter, D. A., Roelofs, W. L., Oyals, B. M., SAlsbury, G. A., SchifF, N. M., Shetlar, D. J., Skinner, M., SParks, B. L., SutScheK, J. A., SutScheK, T. P., SWier, S. R., SYlvia, M. M., Vickers, N. J., VitTUM, P. J., Weidman, R. B., Weber, D. C., Williamson, R. C., and VILlani, M. G. 2006. Trapping Phyllophaga spp. (Coleoptera: Scarabaeidae: Melolonthinae) with sex attractants in the United States and Canada. J. Insect Sci. 6:124.

Roelofs, W. L., Du, J. W., TANG, X. H., RobBins, P. S., and ECKENRODE, C. J. 1985. Three European corn borer populations in New York based on sex pheromones and voltinism. J. Chem. Ecol. 11:829-836.

Roelofs, W., Glover, T., Tang, X.-H., Sreng, I., Robbins, P., Eckenrode, C., Löfstedt, C., Hansson, B., and Bengtsson, B. O. 1987. Sex pheromone production and perception in European corn borer moths is determined by both autosomal and sex-linked genes. Proc. Natl. Acad. Sci. USA 84:7585-7589.

Tóth, M., LÖFstedt, C., Blair, B. W., Cabello, T., Farag, A. I., Hansson, B. S., Kovalev, B. B., Maini, S., Nesterov, E. A., Pajor, I., SAzonov, A. P., Shamshev, I. V., SubcheV, M., and SzÖCS, G. 1992. Attraction of male turnip moths Agrotis segetum (Lepidoptera: Noctuidae) to sex pheromone components and their mixtures at 11 sites in Europe, Asia, and Africa. J. Chem. Ecol. 18:1337-1347.

WoODRUFF, R. E., and BECK, B. E. 1989. Arthropods of Florida and Neighboring Land Area: the Scarab Beetles of Florida (Coleoptera: Scarabaeidae). Part II. The May or June Beetles (genus Phyllophaga), vol. 13. Florida Department of Agriculture and Consumer Services, Tallahassee, FL(226 pp).

Wu, W., Cottrell, C. B., Hansson, B. S., and Löfstedt, C. 1999. Comparative study of pheromone production and response in Swedish and Zimbabwean populations of turnip moth, Agrotis segetum. J. Chem. Ecol. 25:177-196.

Zhang, A., Robbins, P. S., Leal, W. S., Linn, C. E., Villani, M. G., and RoELOFS, W. L. 1997. Essential amino acid methyl esters: major sex pheromone components of the cranberry white grub, Phyllophaga anxia (Coleoptera: Scarabaeidae). J. Chem. Ecol. 23:231-245. 